\title{
SEQUELAS DO COVID 19 EM GUSTAÇÃO E OLFATO: UMA BREVE REVISÃO BIBLIOGRÁFICA
}

\section{REVISÃO BIBLIOGRÁFICA}

CHAVES, leda Bezerra ${ }^{1}$, FECURY, Amanda Alves², OLIVEIRA, Euzébio de ${ }^{3}$, DENDASCK, Carla Viana ${ }^{4}$, DIAS, Claudio Alberto Gellis de Mattos ${ }^{5}$

CHAVES, leda Bezerra. Et al. Sequelas do COVID 19 em gustação e olfato: uma breve revisão bibliográfica. Revista Científica Multidisciplinar Núcleo do Conhecimento. Ano. 06, Ed. 11, Vol. 01, pp. 150-166. Novembro 2021. ISSN: 24480959, Link de acesso: https://www.nucleodoconhecimento.com.br/saude/sequelasdo-covid-19, DOI: 10.32749/nucleodoconhecimento.com.br/saude/sequelas-do-covid19

\section{RESUMO}

Vírus é um ser vivo que não é formado por estrutura celular. Os vírus podem ser transmitidos por contato direto com indivíduos infectados ou de forma indireta por superfícies contaminadas. Definido como uma nova variedade de coronavírus, a COVID 19 fez a Organização Mundial de Saúde (OMS) declarar no começo de 2020 crise na saúde pública global. Considerando-se a alta transmissibilidade deste vírus, foi necessário adotar medidas com intuito de impedir a transmissão e infecção. Os sintomas causados pela COVID-19, em geral, são febre, tosse seca, falta de ar (dispneia), cansaço (fadiga), dor de garganta, dor de cabeça e diarreia. Outros

\footnotetext{
${ }^{1}$ Estudante do Ensino Médio Técnico Integrado em Alimentos do Instituto de Ensino Básico, Técnico e Tecnológico do Amapá (IFAP).

${ }^{2}$ Biomédica, Doutora em Doenças Topicais, Professora e pesquisadora do Curso de Medicina do Campus Macapá, Universidade Federal do Amapá (UNIFAP).

${ }^{3}$ Biólogo, Doutor em Doenças Topicais, Professor e pesquisador do Curso de Educação Física da, Universidade Federal do Pará (UFPA).

${ }^{4}$ Teóloga, Doutora em Psicanálise Clínica. Atua há 15 anos com Metodologia Científica ( Método de Pesquisa) na Orientação de Produção Científica de Mestrandos e Doutorandos. Especialista em Pesquisas de Mercado e Pesquisas voltadas à área da Saúde. Doutoranda em Comunicação e Semiótica (PUC SP).

${ }^{5}$ Biólogo, Doutor em Teoria e Pesquisa do Comportamento, Professor e pesquisador do Curso de Licenciatura em Química do Instituto de Ensino Básico, Técnico e Tecnológico do Amapá (IFAP) e do Programa de Pós Graduação em Educação Profissional e Tecnológica (PROFEPT IFAP).

RC: 100510
}

Disponível em: https://www.nucleodoconhecimento.com.br/saude/sequelas-do-covid-19 
sintomas, em menor escala são anosmia (perda do olfato), hiposmia (diminuição do olfato) e ageusia (perda do sentido do paladar). $O$ objetivo deste foi fazer uma revisão dos últimos dois anos sobre as sequelas do COVID 19 em gustação e olfato. Foi realizada uma breve revisão bibliográfica em artigos científicos sobre as sequelas do COVID 19 em gustação e olfato, entre 2020 e 2021, em língua portuguesa, na base de dados de pesquisa Google Acadêmico. As mulheres e o jovens são os mais atingidos pelas sequelas de gustação e olfato causadas pelo COVID-19. não há tratamentos específicos e cientificamente comprovados às variadas disfunções, mas o mais indicado é a prática do treinamento olfativo. Os estudos relacionados às disfunções são limitados, principalmente, no Brasil e quando são analisados como sequelas. A continuidade das pesquisas científicas é indispensável, pois somente esse processo será capaz de elucidar as dúvidas ainda existentes e gerar tratamentos adequados às pessoas que desenvolveram a COVID-19.

Palavras- chave: Vírus, COVID 19, Disosmia, Disgeusia.

\section{INTRODUÇÃO}

Vírus é um ser vivo que, diferente dos demais, não é formado por célula. Ele possui, geralmente, um ácido nucleico (que pode ser DNA ou RNA), recoberto por uma "cápsula" de proteína. Alguns ainda são recobertos por "pedaços" de membrana da célula, que criam um "envelope" ao seu redor. São muitas vezes menores que uma célula e as parasitam, entrando nelas, e usando as suas estruturas para produzir mais vírus (são parasitas intracelulares obrigatórios) (Brandão, 2015; They, 2020).

Os vírus podem ser transmitidos por contato direto com indivíduos infectados ou de forma indireta por superfícies contaminadas. Eles são transmitidos de um indivíduo para o outro através de gotículas de água na forma de vapor liberadas na respiração ou durante o processo de tosse ou espirro. Gotículas menores liberadas junto com o vapor de água durante esses processos ficam em suspensão no ar espalhando o vírus por áreas maiores e por mais tempo. (Brasil, 2021). Em contato com um desses meios de transmissão os vírus invadem as células mucosas das vias respiratórias e digestórias (Stephens et al., 2009; Silva et al., 2020).

RC: 100510

Disponível em: https://www.nucleodoconhecimento.com.br/saude/sequelas-do-covid-19 
Para ser reproduzir os vírus se ligam a superfície da membrana da célula. Após essa ligação ele pode penetrar na célula ou pode "injetar" o seu material genético (DNA ou RNA) no citoplasma dela. Uma vez dentro das células o material genético do vírus é copiado várias vezes, utilizando as reações químicas que ela consegue fazer. Do mesmo modo, outras reações químicas da célula são usadas para fazer as "capas" de proteína (capsídeos). Assim novos vírus são montados dentro de uma célula e, para saírem e invadirem novas células, rompem a membrana das que os fabricou (They, 2020; Silva et al., 2020a).

Definido como uma nova variedade de coronavírus, a COVID 19 fez a Organização Mundial de Saúde (OMS) declarar no começo de 2020 crise na saúde pública global (Souza et al., 2020). Esses vírus, com elevada taxa de transmissão, são constituídos por envelopes de lipídios e proteínas (pedaço da membrana de uma célula), e capsídeos de proteínas, com uma única fita de RNA (ácido nucleico), e com formato externo de coroa (Silva et al., 2020). Fazem parte da família de vírus geradores de resfriados comuns até infecções mais severas, como a Síndrome Respiratória do Oriente Médio (MERS) e a Síndrome Respiratória Aguda Grave (SARS) (Brasil, 2021; 2021a).

Considerando-se a alta transmissibilidade deste vírus, é necessário adotar medidas com intuito de impedir a transmissão e infecção. Entre algumas dessas ações preventivas, destaca-se a não permanência em locais fechados e isolamento de pessoas infectadas (Stephens et al., 2009).

As maneiras consideradas como as mais eficientes e evitar a contaminação (profilaxia) incluem: a lavagem das mãos, o distanciamento social, o arejamento dos ambientes e sua exposição à luminosidade solar, a limpeza dos objetos e superfícies, a proibição de aglomerações, e o uso de máscaras (bloqueadoras eficientes das gotículas respiratórias dispersas, mesmo em distâncias reduzidas com contato direto ou indireto) (Garcia, 2020). Essas medidas de controle são comprovadamente eficazes, por meio de análises e estudos científicos, na redução de contaminação e disseminação viral (Soares et al., 2021). 
Os sintomas causados pela COVID-19, em geral, são febre, tosse seca, falta de ar (dispneia), cansaço (fadiga), dor de garganta, dor de cabeça e diarreia (Silva et al., 2020). Outros sintomas, em menor escala são anosmia (perda do olfato), hiposmia (diminuição do olfato) e ageusia (perda do sentido do paladar) (Iser et al., 2020).

Sequelas podem ser definidas como mudança no funcionamento das células e/ou na forma e funcionamento dos órgãos causando um defeito permanente ou não no indivíduo (Filho, 2011; Vana e Schiozer, 2013).

Entre as diversas sequelas constatadas nos indivíduos que tiveram COVID19 encontram-se as de cunho psicológico e biológico, como, por exemplo, alterações nos sistemas respiratório, cardiovascular, possíveis alterações cutâneas e neurológicas (depressão e ansiedade) (Estrela et al., 2021).

Um conjunto de pesquisas cientificas apontam danos de longo prazo (após 6 semanas ou persistindo além de 6 semanas do início dos sintomas do coronavírus) no sistema sensorial, com ênfase às sequelas olfativas e gustativas, por exemplo, disosmia (percepção distorcida dos cheiros) e disgeusia (percepção distorcida dos gostos dos alimentos). Pode haver ainda distúrbios do metabolismo (reações químicas) da glicose, hiperlipidemia (aumento da quantidade de gordura no sangue), desregulação do metabolismo (reações químicas) lipídico, pós- transtorno de estresse traumático (um dos tipos de transtornos de ansiedade) e capacidade pulmonar afetada, danos no sistema hepático (fígado) e renal (rins), e possivelmente no reprodutor (Sesapr, 2020; Grendene et al., 2021).

As disfunções no olfato apresentam uma classificação quantitativa, na qual se tem a anosmia (não detecção de odores), hiposmia (limitação na detecção dos odores), hiperosmia (aumento na capacidade de detecção de odores) e disosmia (percepção distorcida dos odores) (Cardoso, 2018). Enquanto que as disfunções quantitativas na gustação podem ser classificadas em hipogeusia (detecção parcial da gustação), hipergeusia (aumento na capacidade de percepção gustativa), ageusia (perda total da gustação) e disgeusia (distorção na gustação) (Barros et al., 2015; Gomes et al., 2020; Machado e Machado, 2020).

RC: 100510

Disponível em: https://www.nucleodoconhecimento.com.br/saude/sequelas-do-covid-19 
A subclassificação qualitativa da disosmia (alteração olfativa) é diversa, entre os exemplos pode-se encontrar a parosmia (percepção distorcida e desagradável dos odores), a fantosmia (percepção de odor na ausência de partículas odoríferas) e agnosmia (incapacidade de classificar os diferentes odores) (Cardoso, 2018). A disgeusia (alteração gustativa) tem uma subclassificação qualitativa, também, diversificada, entre os exemplos, a parageusia (percepção inadequada da gustação ocasionada por estímulo) e a fantogeusia (percepção gustativa desagradável na ausência de estímulo) (Machado e Machado, 2020).

Apesar dos apontamentos são necessários mais estudos em relação às numerosas e diversas sequelas em razão da Covid-19 (Grendene et al., 2021), incluindo os afetados com sintomas reduzidos e os assintomáticos (Uzun, 2020).

\section{OBJETIVO}

Fazer uma revisão bibliográfica dos últimos dois anos sobre as sequelas da COVID 19 em gustação e olfato.

\section{MÉTODO}

Foi realizada uma breve revisão bibliográfica em artigos científicos sobre as sequelas da COVID 19 em gustação e olfato, entre 2020 e 2021, em língua portuguesa, na base de dados de pesquisa Google Acadêmico. Para tal utilizou-se as palavras-chave (ou descritores) "Gustação e COVID19" e "Olfato e COVID 19". Foram encontrados 1777 resultados e utilizados 10 artigos para compor esta breve revisão. Isso possibilitou que a revisão fosse feita baseada nas mais atualizadas produções acadêmicas (Capes, 2012).

Foram utilizados, como critérios de inclusão, artigos com conteúdo COVID 19 e sequelas em gustação e olfato, em língua portuguesa, dentro do período limite da revisão. Foram excluídos artigos que não atendiam a esse conteúdo e/ou período de tempo. 


\section{RESULTADOS E DISCUSSÃO}

A tabela 01 mostra a quantidade de artigos encontrados por descrito e a quantidade de artigos utilizados dentro dos critérios metodológicos.

Tabela 1 - Quantidade de artigos encontrados na base de dados segundo descritores e artigos utilizados

\begin{tabular}{|c|c|c|c|c|}
\hline BASE DE DADOS & DESCRITOR & \begin{tabular}{|c|} 
NUMERO \\
ARTIGOS \\
ENCONTRADOS \\
\end{tabular} & $\begin{array}{c}\text { NUMERO } \\
\text { ARTIGOS } \\
\text { UTILIZADOS }\end{array}$ & \begin{tabular}{|c|} 
AUTOR E ANO DOS \\
ARTIGOS \\
UTILIZADOS
\end{tabular} \\
\hline \multirow{10}{*}{ Google acadêmico } & \multirow{7}{*}{ Gustação e COVID19 } & \multirow{7}{*}{237} & \multirow{7}{*}{7} & PIMENTEL, 2020 \\
\hline & & & & $\begin{array}{l}\text { GRENDENE et al., } \\
2021\end{array}$ \\
\hline & & & & SANTOS et al., 2020 \\
\hline & & & & COSTA et al., 2020 \\
\hline & & & & SOUZA et al., 2021 \\
\hline & & & & $\begin{array}{c}\text { NOGUEIRA et al., } \\
2021\end{array}$ \\
\hline & & & & NUNES et al., 2020 \\
\hline & \multirow{3}{*}{ Olfato e COVID 19} & \multirow{3}{*}{1540} & \multirow{3}{*}{3} & KOSUGI et al., 2020 \\
\hline & & & & BRITO e SLVA, 2020 \\
\hline & & & & $\begin{array}{c}\text { LOPES e DE ABREU, } \\
2021\end{array}$ \\
\hline
\end{tabular}

A tabela 02 mostra os métodos utilizados em cada artigo selecionado para esta revisão, os resultados e as conclusões encontradas.

RC: 100510

Disponível em: https://www.nucleodoconhecimento.com.br/saude/sequelas-do-covid-19 


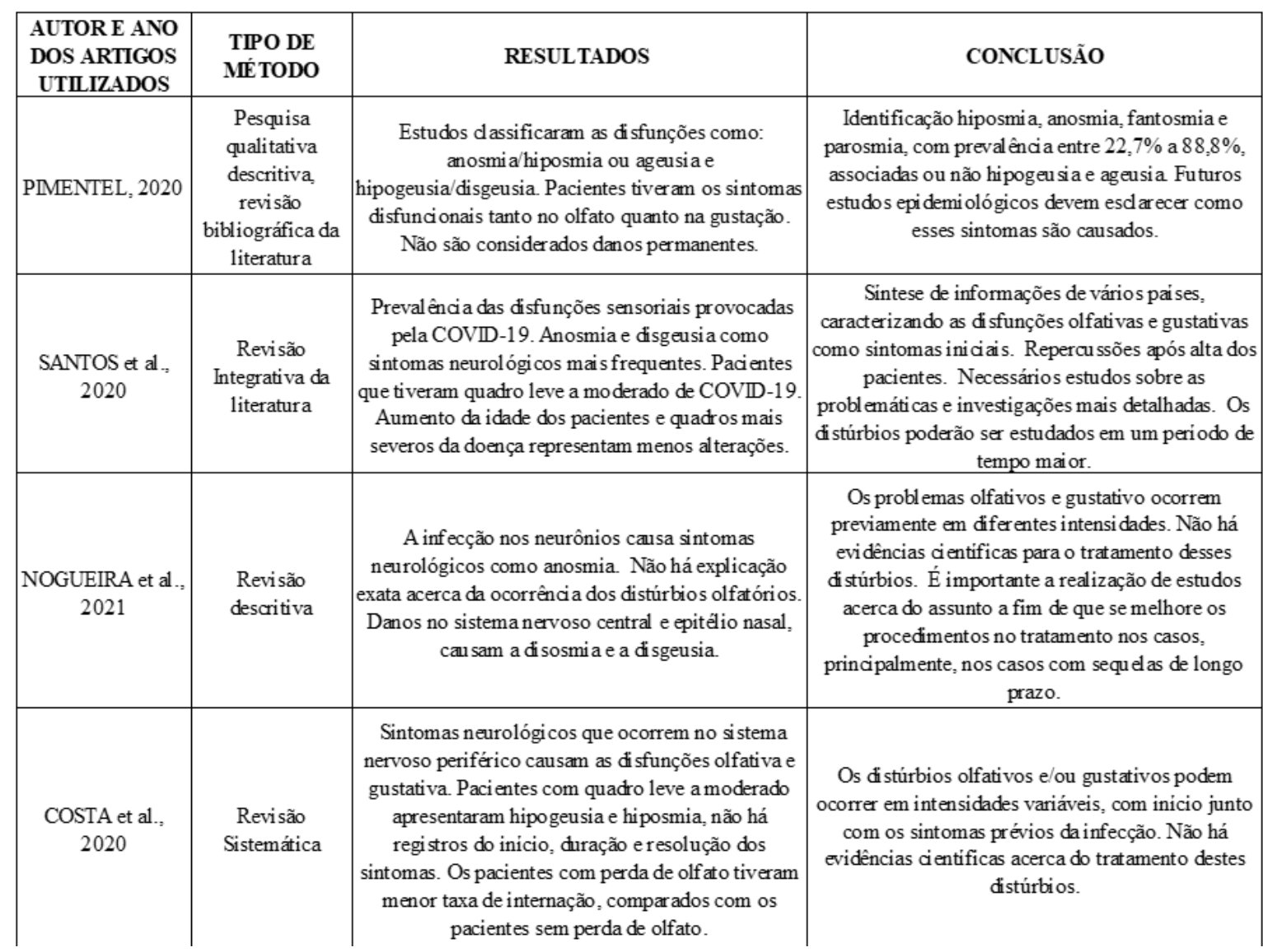




\begin{tabular}{|c|c|c|c|}
\hline $\begin{array}{c}\text { BRITO e SIVA, } \\
2020\end{array}$ & $\begin{array}{c}\text { Revisão da } \\
\text { literatura }\end{array}$ & $\begin{array}{l}\text { Associação de manifestações neurológicas e a } \\
\text { COVID-19. Entre elas os distúrbios do olfato e } \\
\text { paladar, como a hiposmia a anosmia, a disgeusia, } \\
\text { hipogeusia e ageusia. Os mecanismos exatos da } \\
\text { neuroinvasão causada pela COVID-19 ainda são } \\
\text { desconhecidos. }\end{array}$ & $\begin{array}{l}\text { Ocorre uma inci dência maior de danos no sistema } \\
\text { nervoso em quadros agudos da virose. Entretanto a } \\
\text { classificação dos casos agudos e crônicos ainda hoje } \\
\text { não é consenso. São necessários mais estu dos sobre } \\
\text { as sequelas a longo prazo. }\end{array}$ \\
\hline $\begin{array}{c}\text { SOUZA et al., } \\
2021\end{array}$ & Relato de casos & $\begin{array}{c}\text { Ano smia nos pacientes é uma manifestação } \\
\text { sintomal ógica recorrente. Fundamental a descrição } \\
\text { de relatos de casos a fim de esclarecer as } \\
\text { ocorrências de sequel as gustativas olfativas com } \\
\text { objetivo de realializar o manejo da recuperação. }\end{array}$ & $\begin{array}{l}\text { As disfunções devem ser estudadas com maior rigor } \\
\text { e por maior perio do de tempo. A COVID-19 afeta } \\
\text { as células do epitélio olf ativo, possivelmente } \\
\text { alterando a neurotransmissão. }\end{array}$ \\
\hline $\begin{array}{l}\text { LOPES e DE } \\
\text { ABREU } 2021\end{array}$ & $\begin{array}{c}\text { Metodologia para } \\
\text { tratamento }\end{array}$ & $\begin{array}{l}\text { Possiveis danos neurológicos em nivel celular } \\
\text { decorrentes da COVID-19. Pacientes recuperados } \\
\text { ainda relatam alterações, que podem ser } \\
\text { irreversiveis, nos senti dos olfativo e gustativo. }\end{array}$ & $\begin{array}{l}\text { As sequelas causadas pela doença podem ser de } \\
\text { cunho neurológicos, em nivel celular ou não. Isso } \\
\text { pode causar transtornos, sindromes e outras } \\
\text { variáveis futuramente. }\end{array}$ \\
\hline $\begin{array}{c}\text { NUNES et al., } \\
2020\end{array}$ & $\begin{array}{l}\text { Revisão } \\
\text { Integrativa }\end{array}$ & $\begin{array}{c}\text { Disfunções olfativas com preval ência entre } 30 \text { a } \\
88 \% \text { dos pacientes com COVID-19 englobados nos } \\
\text { diferentes estudos. Relados por pacientes com } \\
\text { quadros leves e moderados da doença. Os } \\
\text { transtornos como anosmia, hiposmiahipogeusia, e } \\
\text { disgeusia são sintomas frequentes nos pacientes } \\
\text { com COVID-19. }\end{array}$ & $\begin{array}{l}\text { Oenvolvimento do virus com o sistema nervoso é, } \\
\text { até então, inconclusivo. Entender os sintomas } \\
\text { neurológicos, principalmente em quadros mais } \\
\text { graves, auxilia nas intervenções e nos prognósticos } \\
\text { médicos. }\end{array}$ \\
\hline $\begin{array}{c}\text { GRENDENE et } \\
\text { al., } 2021\end{array}$ & $\begin{array}{c}\text { Revisão } \\
\text { bibliográfica }\end{array}$ & $\begin{array}{c}\text { Aponta que existem poucos estudos revi sados sobre } \\
\text { a ocorrência ou prevalência das sequelas de longo } \\
\text { prazo da COVID-19. Há algumas evidências de que } \\
\text { disfunções como a disosmia e đisgeusia são } \\
\text { sequelas de longo prazo associadas à COVID-19. A } \\
\text { mai oria não trabalha com periodos de } \\
\text { acompanhamento indi cativos de sequel as de longo } \\
\text { prazo. }\end{array}$ & $\begin{array}{l}\text { Não se sabe muito sobre estratégias para tratamento } \\
\text { para este virus. Pesquisas clini cas estão sendo } \\
\text { realizadas para descobrir novos tratamentos. } \\
\text { Prevenção ainda é a melhor forma de li dar. }\end{array}$ \\
\hline $\begin{array}{l}\text { KOSUGI et al ., } \\
2020\end{array}$ & $\begin{array}{l}\text { Quali quantitativa } \\
\text { por questionário }\end{array}$ & $\begin{array}{l}\text { Induidos } 253 \text { pacientes, de todas as regiões } \\
\text { br asileiras, uma maioria apresentou anosmia e } 13 \text {, } \\
2 \% \text { não tiveram recuperação da perda olfativa } \\
\text { Alteração no paladar não está induida na pesquisa. }\end{array}$ & $\begin{array}{l}\text { Anosmia apresenta menor taxa de recu peração e } \\
\text { duração mai or em pacientes por COVID-19 } \\
\text { positivos do que nos negativos. Hiposmia teve } \\
\text { maior taxa de recuper ação do que a anosmia. }\end{array}$ \\
\hline
\end{tabular}

Através dos estudos de Pimentel (2020) com base em 15 publicações que descreveram relatos clínicos na Europa no início de 2020, foram identificados casos de hiposmia, anosmia, fantosmia e parosmia, com prevalência entre $22,7 \%$ a $88,8 \%$, associadas ou não hipogeusia e ageusia.

A amplitude das taxas de sintomas/sequelas sensoriais se deve a diferença entre os estudos, assim como os instrumentos utilizados por estas variadas pesquisas científicas, e até mesmo diferenças genéticas na população (Pimentel, 2020). As diferenças populacionais demonstram que as taxas de ocorrência das anormalidades olfativo-gustativas são maiores, por exemplo, nas populações da Europa, Norte da África, Sul asiático e Ásia ocidental, em comparação com as menores taxas apresentadas pelos pacientes da Ásia oriental (Santos et al., 2020). As pessoas do sexo feminino e as pessoas mais jovens parecem ser as mais atingidas pelos RC: 100510 
distúrbios olfativos e gustativos (Costa et al., 2020; Nascimento, 2020). Essa diferença provavelmente ocorre porque existe uma diferença de reação fisiológica de defesa entre as faixas etárias e os gêneros da espécie humana (Cardoso et al., 2020).

O trabalho de Santos et al. (2020) destaca que as disfunções olfativas e gustativas como sintomas iniciais, e que tem maior repercussão após alta dos pacientes.

O tratamento hospitalar dos pacientes se encerra antes do aparecimento das sequelas, provavelmente porque há uma deficiência histórica de vagas e de profissionais de saúde no Brasil. O aumento do fluxo hospitalar de pacientes durante a pandemia parece ter agravado a situação, impedindo um acompanhamento específico e minucioso, pois o atendimento já era precário (Santo et al., 2021).

$\mathrm{Na}$ revisão integrativa de Nogueira et al. (2021) identificou-se que os problemas olfativos e gustativos ocorrem previamente em diferentes intensidades. Não há evidências científicas para o tratamento desses distúrbios.

Costa et al. (2020) identificaram que s distúrbios olfativos e/ou gustativos podem ocorrer em intensidades variáveis, com início junto com os sintomas prévios da infecção. Não há evidências científicas acerca do tratamento destes distúrbios.

O sistema imunológico humano varia de acordo com algumas características físicas e fisiológicas (Cardoso et al., 2020). A intensidade dos sintomas pode ocorrer devido a essas variações. Nas mulheres os hormônios produzidos nos ciclos menstruais, os presentes na pílula anticoncepcional e no tratamento de reposição hormonal (para combater os sintomas da menopausa) afetam o sistema de defesa, tornando-o diferente do dos homens (Rogero et al., 2021).

A idade também é um fator para a diferença de aparecimento dos sintomas. Em contraponto à Costa et al. (2020) e Nascimento (2020), uma idade mais avançada parece ser mais suscetível aos sintomas causados pelo vírus. Um intestino com mais idade normalmente apresenta uma menor absorção de nutrientes e de produção de células de defesa. A diferença de conceito entre os autores pode ser relativa ao tipo específico de sintoma (Rogero et al., 2021).

RC: 100510

Disponível em: https://www.nucleodoconhecimento.com.br/saude/sequelas-do-covid-19 
O estresse também afeta a função imunológica de defesa. O sistema nervoso influencia a produção e liberação de hormônios que podem mediar essa função (Rogero et al., 2021). Pessoas mais jovens, por sua menor vivência, podem ser mais afetadas pelo estresse.

Quanto aos tratamentos estudados na ação contra os distúrbios olfativos e gustativos, na literatura apresenta-se o uso de corticoides (ação anti-inflamatória) nasais e orais, treinamento olfatório, vitamina $\mathrm{A}$ e citrato de sódio. Existem outras alternativas terapêuticas, mas as apresentadas anteriormente são mais propícias à efetividade. Apesar disso, não há evidências concretas ou suficientes acerca da eficácia desses tratamentos (Cardoso et al., 2020; Costa et al., 2020; Felipe et al., 2021; Neta et al., 2021).

Mediante a uma revisão bibliográfica, (Brito e Silva, 2020), acreditam que ocorre uma incidência maior de danos no sistema nervoso em quadros agudos da virose. Entretanto a classificação dos casos agudos e crônicos ainda hoje não é consenso.

Souza et al. (2021) chegaram à conclusão que as disfunções devem ser estudadas com maior rigor e por maior período de tempo. A COVID-19 afeta as células do epitélio olfativo, possivelmente alterando a neurotransmissão.

O estudo de Lopes e De Abreu (2021) informa que as sequelas causadas pela doença podem ser de cunho neurológicos, em nível celular ou não. Isso pode causar transtornos, síndromes e outras variáveis futuramente.

As disfunções olfativas e gustativas, em geral, ocorrem de maneira associadas, uma vez que os sentidos olfativo e gustativo (sentidos químicos, percebem as substâncias na cavidade nasal e oral) trabalham em conjunto e as sensações gustativas dependem exclusivamente do olfato. As sensações sensoriais acontecem devido a interação de moléculas com os receptores do olfato e da gustação. Os receptores gustativos (encontrados em regiões da língua, palato, faringe, epiglote e esôfago) são responsáveis por mandar as informações gustativas através de impulsos nervosos (comunicação entre células, os neurônios) ao sistema nervoso central. No olfato, a informação olfativa também é transmitida ao sistema nervoso central por meio de RC: 100510

Disponível em: https://www.nucleodoconhecimento.com.br/saude/sequelas-do-covid-19 
neurônios que se comunicam por correntes elétricas (sinapses) (Neto et al., 2011; Oliveira, 2014).

O vírus do COVID19 causa lesão nas células neurais olfatórias, pois no epitélio nasal encontram-se quantidade elevada das enzimas que facilitam a difusão e replicação dele. Em resposta à infecção o sistema imunológico "ativa" o sistema de defesa por citosinas (proteínas), o chamado efeito citopático, o que pode comprometer o processo de neurotransmissão, causando a perda olfativa. Isso também ocorre com a gustação, onde o processo inflamatório (efeito citopático) diminui o tempo de vida das células receptoras das papilas gustativas (Cardoso et al., 2020; Felipe et al., 2021)

Análises científicas demonstram a probabilidade de o vírus atingir o epitélio nasal, não os neurônios diretamente. As células do epitélio nasal conservam o denominado equilíbrio iônico do muco, do qual os neurônios dependem para fazer as sinapses até o sistema nervoso central. Quando esse equilíbrio é prejudicado o olfato deixa de funcionar como deveria, podem ocorrer danos nos neurônios olfativos. Ainda assim, não há comprovação se a anosmia decorre diretamente do vírus ou se é fruto de uma resposta imunológica (Nishioka, 2020).

No sentido gustativo, as células receptoras gustativas não são afetadas pelo vírus, mas sim as células de sustentação, o que pode explicar os casos de perda da gustação. O epitélio olfatório tem a capacidade de se regenerar, ou seja, a anosmia é considerada reversível, contudo, os pacientes com recuperação lenta dessa disfunção podem apresentar outro distúrbio, a parosmia, na qual os sabores (doce, amargo, salgado, azedo) são recuperados, mas determinados odores e aromas tornam-se desagradáveis (Nishioka, 2020).

Nunes et al. (2020), em sua revisão, constataram que o envolvimento do vírus com o sistema nervoso é, até então, inconclusivo. Entender os sintomas neurológicos, principalmente em quadros mais graves, auxilia nas intervenções e nos prognósticos médicos.

O envolvimento do vírus com o sistema nervoso parece ser inconclusivo. Atualmente, há duas teorias principais que explicam os impactos neurológicos da COVID-19 no RC: 100510

Disponível em: https://www.nucleodoconhecimento.com.br/saude/sequelas-do-covid-19 
ser humano, a primeira corresponde à atuação do vírus na desregulação imune, como o excesso de produção de citosinas, e assim, causando os sintomas neurológicos. Apontando-se a possibilidade do vírus se propagar por vias sanguíneas e vias neurais até o sistema nervoso. A segunda sugere que a infecção no sistema nervoso central ocorre por meio dos neurônios periféricos infectados pelo vírus (Felipe et al., 2021).

Brito e Silva (2020), Pimentel (2020), Santos et al. (2020) e Nogueira et al. (2021) concordam sobre o pouco conhecimento hoje existente e propõem a continuidade dos estudos acerca dos sintomas do COVID 19. Isso é importante porque através dos estudos científicos será possível definir as causas dos mecanismos que provocam as alterações olfativo-gustativas e fornecer base para a pesquisa de tratamentos adequado aos afetados (Nishioka, 2020; Santos et al., 2020; Felipe et al., 2021; Lima et al., 2021; Oliveira et al., 2021).

Na revisão bibliográfica de Grendene et al. (2021) a conclusão indica que não se sabe muito sobre estratégias para tratamento para este vírus. Por isso pesquisas clínicas estão sendo realizadas para descobrir novos tratamentos. A prevenção, hoje, ainda é a melhor forma de lidar com a infecção.

As medidas de prevenção contra o vírus incluem: a higienização das mãos frequentemente, feita por meio da lavagem com água e sabão (quebra parede lipídica do vírus e o mata) e/ou uso de álcool etílico 70\%, evitar contanto das mãos com olhos, nariz e boca, praticar etiqueta respiratória (cuidados ao tossir ou espirrar), usar máscaras faciais (barreira física contra as gotículas em suspensão), distanciamento social de pelo menos um metro, desinfecção de objetos e superfícies, sintomáticos manter-se em isolamento, arejar ambientes fechados, evitar apertos de mãos e abraços e evitar contato social. Todos são indicados de acordo com embasamento científico (Stephens et al., 2009; Baptista e Fernandes, 2020; Garcia, 2020; Soares et al., 2021; Spdm, 2021)

Em relação ao isolamento social, estudos apontam sua eficácia e auxílio na redução das taxas de infecção, no entanto, deve ser feito em associação com as demais meditas de contenção do vírus (Oms, 2021). Existem comprovações, também, acerca 
do arejamento de locais fechados ao expor à luz solar e mantê-los ventilados, pois tais ambientes contêm as gotículas de vapor d'água advindas da tosse, espirro e do próprio ato de falar dos indivíduos, (Opas, 2021). O uso de máscaras é cientificamente comprovado, sabe-se que esse EPI (equipamento de proteção individual) é uma barreira física, uma parede, contra o vírus da COVID-19 (Salles et al, 2021). Além disso, enfatiza-se que mesmo após vacinar-se as pessoas não devem deixar de utilizar/aplicar os mecanismos de prevenção contra o vírus (Brasil, 2021a).

Kosugi et al. (2020) realizaram uma pesquisa online e concluíram que anosmia apresenta menor taxa de recuperação e duração maior em pacientes por COVID-19 positivos do que nos negativos. Hiposmia teve maior taxa de recuperação do que a anosmia.

$\mathrm{Na}$ hiposmia, por ser uma perda parcial, é possível "treinar" o olfato. Odores e óleos essenciais são utilizados duas vezes ao dia por seis meses, com esse intuito. Já perda mais severa, anosmia, caso não exista uma recuperação instantânea o tratamento é medicamentoso e prolongado (Pereira et al., 2020). Isso provavelmente explica a diferença nas taxas de recuperação de ambas as sequelas

\section{CONCLUSÕES}

As sequelas do COVID-19 são distúrbios diversos que comprometem os sentidos sensoriais (olfato e gustação) em diferentes graus, afetando o bem-estar e o cotidiano de milhares de pessoas.

As mulheres e o jovens são os mais atingidos por estas disfunções. Não se sabe com exatidão como o vírus ocasiona os sintomas neurológicos nos pacientes, e os meios exatos pelos quais ocorrem as disfunções. Também, não há tratamentos específicos e cientificamente comprovados às variadas disfunções, mas o mais indicado é a prática do treinamento olfativo.

Os estudos relacionados às disfunções são limitados, principalmente, no Brasil e quando são analisados como sequelas, ou seja, estudadas após determinado período posterior à recuperação dos pacientes da COVID-19. A continuidade das pesquisas RC: 100510

Disponível em: https://www.nucleodoconhecimento.com.br/saude/sequelas-do-covid-19 
científicas é indispensável, pois somente esse processo será capaz de elucidar as dúvidas ainda existentes e gerar tratamentos adequados às pessoas que desenvolveram a COVID-19 e ficaram com alguns dos variados tipos de sequelas, incluindo as sensoriais.

\section{REFERÊNCIAS}

BAPTISTA, A. B.; FERNANDES, L. V. COVID-19, análise das estratégias de prevenção, cuidados e complicações sintomáticas. Revista Desafios, v. 7, p. 110, 2020.

BARROS, Ó. D. et al. Disgeusia: a propósito de um caso clínico. Revista Portuguesa De Medicina Geral E Familiar, v. 31, n. 4, p. 272-276, 2015.

BRANDÃO, R. E. L. Vírus e Retrovírus: Contributo para a Evolução das Espécies. 2015. 61p. (Mestrado). Faculdade de Ciências da Saúde, Universidade Fernando Pessoa, Porto PT.

BRASIL. Coronavírus - Como é transmitido? , Brasília DF, 2021. Disponível em: < https://www.gov.br/saude/pt-br/coronavirus/como-e-transmitido >. Acesso em: 06 set 2021.

. Doenças ocasionadas por vírus respiratórios emergentes, incluindo o COVID-

19. Brasília DF, 2021a. Disponível em: < https://www.unasus.gov.br/cursos/curso/46164 >. Acesso em: 06 set 2021.

BRITO, W. G. F.; SILVA, J. P. D. O. Impactos neuropatológicos do COVID-19. Brazilian Journal of Health Review, v. 3, n. 3, p. 4227-4235, 2020.

CAPES. Treinamento no uso do Portal de Periódicos. Brasilia DF, 2012. Disponível em: < https://www.fca.unesp.br/Home/Biblioteca/portal-capes.pdf >. Acesso em: 06 set 2021.

CARDOSO, A. R. Olfato como Marcador Biológico. 2018. 21p. (Mestrado). Universidade de Lisboa, Lisboa PT.

RC: 100510

Disponível em: https://www.nucleodoconhecimento.com.br/saude/sequelas-do-covid-19 
CARDOSO, M. D. C. et al. Anosmia e disgeusia no paciente com coronavírus: revisão narrativa. REAS/EJCH, v. 46, p. 1-8, 2020.

COSTA, K. V. T. D. et al. Desordens olfativas e gustativas na COVID-19: uma revisão sistemática. Braz J Otorhinolaryngol., v. 86, n. 6, p. 781-792, 2020.

ESTRELA, M. C. A. et al. Covid-19: sequelas fisiopatológicas e psicológicas nos pacientes e na equipe profissional multidisciplinar. Brazilian Journal of Development, v. 7, n. 6, p. 59138-59152, 2021.

FELIPE, L. P. et al. Compreensão das manifestações neurológicas induzidas por infecções pelo novo coronavírus: uma revisão integrativa. REAID, v. 95, n. 36, p. e21137, 2021.

FILHO, N. D. A. O que é saúde? Rio de Janeiro RJ: Editora Fiocruz, 2011. 160p.

GARCIA, L. P. Uso de máscara facial para limitar a transmissão da COVID-19. Epidemiol. Serv. Saude, v. 29, n. 2, p. 1-4, 2020.

GOMES, D. R. D. P. et al. Avaliação do paladar de idosos e sua relação com estado nutricional e hábitos alimentares. Pan American Journal of Aging Research, v. 8, n. 1, p. 1-8, 2020.

GRENDENE, C. S.; GULO, R. B.; BETIOL, R. S. M. Coronavírus (covid-19): história, conhecimento atual e sequelas de longo prazo. Revista Corpus Hippocraticum, v. 1, n. 1, p. 1-14, 2021.

ISER, B. P. M. et al. Definição de caso suspeito da COVID-19: uma revisão narrativa dos sinais e sintomas mais frequentes entre os casos confirmados. Epidemiol. Serv. Saude, Brasília, v. 29, n. 3, p. 1-11, 2020.

KOSUGI, E. M. et al. Recuperação incompleta e tardia da perda súbita do olfato na COVID-19. Braz. j. otorhinolaryngol., v. 86, n. 4, p. 490-496, 2020. 
LIMA, J. H. C. et al. Covid-19 e os danos ao aparelho olfatório causando anosmia. Revista Científica Multidisciplinar, v. 2, n. 8, p. e28665, 2021.

LOPES, D. O.; DE ABREU, F. Eletroterapia IVL no tratamento de Covid-19 e sequelas no sistema nervoso central. Brazilian Journal of Development, v. 7, n. 4, p. 42332 423402021.

MACHADO, A. L. M.; MACHADO, M. C. M. Disgeusia: Revisão de Literatura. 2020. 56p. (Graduação). Universidade de Uberaba, Uberaba MG.

NASCIMENTO, M. A. Alteração das funções sensoriais de olfato e paladar e seus correlatos clínicos e funcionais em indivíduos com Covid-19. 2020. 71p. (Mestrado). Universidade Federal do Rio Grande do Norte, Santa Cruz.

NETA, F. I. et al. Pathophysiology and possible treatments for olfactory-gustatory disorders inpatients affected by COVID-19. Current Research in Pharmacology and Drug Discovery, v. 2, p. 1-11, 2021.

NETO, F. X. P. et al. Anormalidades sensoriais: Olfato e paladar. Arquivos Int. Otorrinolaringol., v. 15, n. 3, p. 350-358, 2011.

NISHIOKA, S. D. A. A perda de olfato na COVID-19 já tem explicação - pelos menos em $\quad 2020.2$ Disponível em: < https://www.unasus.gov.br/especial/covid19/markdown/335 >. Acesso em: 30 out 2021.

NOGUEIRA, J. F. et al. Distúrbios olfatórios decorrentes de infecção por SARS-CoV2: fisiopatologia, fatores de risco e possíveis intervenções. Research, Society and Development, v. 10, n. 11, p. 1-7, 2021.

NUNES, L. T. D. et al. Principais Manifestações Neurológicas decorrentes do COVID19: uma revisão integrativa. Revista Saúde Coletiva, v. 10 , n. 59 , p. $4248-$ 4254, 2020. 
OLIVEIRA, A. A. D. et al. Análise dos principais fatores de risco preexistentes em pacientes diagnosticados com a COVID-19 no Amapá, Amazônia, Brasil. Revista Científica Multidisciplinar Núcleo do Conhecimento, v. 17, p. 5672, 2021. Disponível em: < https://www.nucleodoconhecimento.com.br/saude/riscopreexistentes $>$.

OLIVEIRA, F. V. Aromas: contextualizando o ensino de Química através do olfato e paladar. 2014. 137 p. (Mestrado). Universidade de Santa Maria, Santa Maria RS.

OMS. Série de documentos de informação sintéticos do escritório regional da oms para a áfrica sobre a COVID-19. Africa, p. 1-6, 2021. Disponível em: < https://apps.who.int/iris/bitstream/handle/10665/338819/WHO-AF-ARD-DAK-102021-por. pdf?sequence=1\&isAllowed=y >. Acesso em: 30 out 2021.

OPAS. Roteiro para melhorar e garantir a boa ventilação de ambientes fechados no contexto da doença causada pelo novo coronavirus, COVID-19. Washington D.C., 2021. Disponível em: < https://iris.paho.org/handle/10665.2/53938 >. Acesso em: 01 out 2021.

PEREIRA, A. C. C. M. et al. Revisão bibliográfica: Anosmia no COVID-19. Revista Cien, v. 15, n. 2, p. 96-, 2020.

PIMENTEL, B. N. As disfunções olfativas e gustativas como apresentação clínica da COVID-19. Research, Society and Development, v. 9, n. 8, p. e64985072, 2020.

ROGERO, M.; NATACCI, L.; AMANCIO, O. Nutrição \& Imunidade. São Paulo SP: SBAN, 2021. 27p.

SANTO, D. M. N. D. E. et al. Desafios do enfermeiro do Centro Cirúrgico frente à pandemia da COVID-19 e transição de uma sala cirúrgica em unidade de terapia semiintensiva. REAS, v. 13, n. 6, p. 1-6, 2021.

SANTOS, I. H. A. et al. Disfunções olfativas e gustativas na COVID-19. Research, Society and Development, v. 9, n. 12, p. e42591211363, 2020. 
SESAPR. Reabilitação do paciente pós tratamento de infecção por SARS- CoV-2. Curitiba $\quad 2020$ PR, Disponível em: < https://www.saude.pr.gov.br/sites/default/arquivos_restritos/files/documento/202012/Nota\%20orientativa\%20n\%C2\%BA\%2053\%20reabilita\%C3\%A7\%C3\%A3o.pdf >. Acesso em: 09 set 2021.

SILVA, A. W. C. et al. Caracterização clínica e epidemiologia de 1560 casos de COVID-19 em Macapá/AP, extremo norte do Brasil. Research, Society and Development, v. 9 , n. 8, p. 1-21, 2020a. Disponível em: < https://rsdjournal.org/index.php/rsd/article/view/5499/4641 >.

SILVA, A. W. C. et al. Perfil epidemiológico e determinante social do COVID-19 em Macapá, Amapá, Amazônia, Brasil. Revista Científica Multidisciplinar Núcleo do Conhecimento, v. 4, n. 4, p. 05-27, 2020. Disponível em: < https://www.nucleodoconhecimento.com.br/saude/covid-19-em-macapa >.

SOARES, K. H. D. et al. Medidas de prevenção e controle da covid-19: revisão integrativa. Revista Eletrônica Acervo Saúde, v. 13, n. 3, p. 1-11, 2021. Disponível em: < https://doi.org/10.25248/reas.e6071.2021 >.

SOUZA, F. D. S. et al. "Anarquia do paladar" e anosmia pós-COVID-19: Seriam danos permanentes? Relato de casos. Revista de Ciências Biológicas e da Saúde, v. 4, n. 1, p. 1-6, 2021.

SOUZA, K. O. et al. Covid-19 e o cenário atual da Cidade de Castanhal PA, Brasil. Research, Society And Development, v. 9, n. 8, p. 1-17, 2020. Disponível em: < https://rsdjournal.org/index.php/rsd/article/view/5717/4998 >.

SPDM. HMB explica por que a higienização das mãos auxilia na prevenção da Covid19. São Paulo SP, 2021. Disponível em: < https://www.spdm.org.br/saude/noticias/item/3390-hmb-explica-por-que-ahigienizacao-das-maos-auxilia-na-prevencao-da-covid-19 >. Acesso em: 04 out 2021. 
STEPHENS, P. R. S. et al. Virologia. In: MOLINARO, E. M.;CAPUTO, L. F. G., et al (Ed.). Conceitos e métodos para a formação de profissionais em laboratórios de saúde. Rio de Janeiro RJ: EPSJV, v.4, 2009. p.125 - 220.

THEY, N. H. Você sabe o que é um vírus? Microbiologando Porto Alegre RS, 2020. Disponível em: < https://www.ufrgs.br/microbiologando/voce-sabe-o-quee-um-virus/ >. Acesso em: 06 set 2021.

UZUN, A. C. D. S. B. Sequelas da Covid-19 vão além da fadiga, ressalta especialista. Campo Grande MS, 2020. Disponível em: < http://www.ms.gov.br/sequelas-dacovid-19-vao-alem-da-fadiga-ressalta-especialista/ >. Acesso em: 06 set 2021.

VANA, L. P. M.; SCHIOZER, W. Sequelas de queimaduras: nova classificação. Rev Bras Queimaduras, v. 12, n. 3, p. 192, 2013.

Enviado: Novembro, 2021.

Aprovado: Novembro, 2021. 